\title{
An analysis of the risk factors for falls, recurrent falls, and fall-related injuries among the elderly in senior Chinese apartments: a cross-sectional study
}

\author{
Qingqing Su \\ Medical School of Chinese PLA \\ Mi Song \\ Medical School of Chinese PLA \\ Jie Zhang \\ Chinese PLA General Hospital \\ Yazhan Mao \\ Medical School of Chinese PLA \\ Jie Song \\ Medical School of Chinese PLA \\ Hongying Pi ( $\triangle 879357401 @ q q . c o m$ ) \\ Chinese PLA General Hospital
}

\section{Research Article}

Keywords: Accidental fall, Risk factors, Risk assessment, Elderly, Senior apartment

Posted Date: September 15th, 2021

DOl: https://doi.org/10.21203/rs.3.rs-882362/v1

License: (9) (i) This work is licensed under a Creative Commons Attribution 4.0 International License. Read Full License 


\section{Abstract \\ Objective}

Falls, recurrent falls, and fall-related injuries among the elderly are severe problems that seriously threaten the quality of life and health in old age. However, there are few studies on fall risks among the elderly living in senior apartments in China. Our study aims to investigate the factors and differences in falls, recurrent falls, and fall-related injuries among these elderly residents, providing a reference for screening those with high fall risks.

\section{Method}

Face-to-face structured interviews were conducted on 331 older adults over 65 years of age living in four senior apartments. We performed comparative analyses on the results of fall events with two separate criteria (falls vs. no falls; number of falls $\leq 1$ and without injury vs. fall-related injuries or number of falls $\geq 2$ ). Several significant variables were involved in a logistic model for regression analysis.

\section{Results}

Falls, recurrent falls, and fall-related injuries among the elderly in senior apartments were independently associated with gender (female), urinary incontinence/frequency, and conscious unsteady gait. Furthermore, fall risks increased with age and the number of risk factors. The AUC, sensitivity, and specificity of the fall risk prediction model were $0.749,82.4 \%$, and $57.1 \%$, respectively.

\section{Conclusions}

Falls among the elderly in senior apartments are affected by several factors. Female elderly with urinary incontinence/frequency and conscious unsteady gait should be prioritized for fall prevention interventions.

\section{Introduction}

With an increase in human life expectancy, the degeneration of physiological functions (e.g., body functions, balance, limb coordination [1]) and other factors (e.g., diseases, drugs, cognitive impairment) lead to a significantly enhanced probability of falls, recurrent falls, and fall-related injuries. Research has shown that about $32 \%$ of falls in the elderly lead to hip fractures, brain injuries, and other severe injuries, being the main causes of decreased activity, independence, quality of life, and thus increased mortality [2, 3]. Although falls in the elderly have received attention over time, they continue to be a global public health problem that needs to be addressed due to the aging population. Falls are the second leading cause of death from accidental injury worldwide and have become the leading cause of death from injury 
among the elderly over 65 years of age in China [4,5]. Due to the harmful effects of falls, people in China often refer to falls in the elderly as "the last fall in life". As the most populous nation in the world, the number of people aged 65 years and above has reached 190.64 million in China. Therefore, China faces more significant challenges in preventing and managing falls among the elderly compared to other nations.

Injuries caused by falls are often considered minor due to the low death rate from falls [6]. However, falls have a high incidence, with a third of the elderly experiencing falls each year [7, 8]. Moreover, injuries caused by falls have a significant impact on the daily life, independence, and mental health of the elderly [9]. It has been shown that even a fall without injury can be a psychological burden for the elderly [10]. Hence, fall prevention and intervention are vital. It has been proven that multi-factor interventions for risks among the elderly can reduce the incidence of falls and their adverse consequences [11]. Recently, researchers have focused on falls in the elderly, particularly on the fall-related factors of specific groups and fall interventions [12-14]. However, there are few reports or studies on falls among the elderly in senior housing. The research on the differences between the risk factors for isolated falls and recurrent falls/fall-related injuries is lacking. The above situation may result from the late emergence of supporting the elderly in senior housing in China.

In China, senior housing arrangements provide professional life and medical care services for the elderly with financial and self-care capabilities, typically in medium to high-end pension-based institutions [15]. Reducing and preventing falls in the elderly is one of the critical components of safety in pension-based institutions and is vital in reducing disputes, improving quality of service, and in the recognition of the benefits of institutional care [16]. Therefore, it is necessary to investigate falls in the elderly in senior apartments. Additionally, some researchers believe that the cause of an isolated fall is more uncertain than that of recurrent falls. Isolated falls are more likely to be affected by the environment or unexpected events, while recurrent falls are more likely to be affected by inherent factors. Consequently, risk interventions for recurrent falls are expected to get better outcomes [17].

This study aims to identify the primary factors and differences among these factors that affect falls, recurrent falls, and fall-related injuries among the elderly in senior apartments by investigating their fall status. The results provide a reference for identifying those at high risk for falls and help develop targeted interventions for fall prevention.

\section{Materials And Methods}

\section{Subjects}

A cross-sectional study was conducted from March to May 2019 on elderly persons at four senior apartments in Beijing who met the inclusion and exclusion criteria. The inclusion criteria were: age $\geq 65$ years; able to walk independently or with assistance; has lived in the apartment for more than one year; subjects or their guardians provided informed consent to participate in the study. The elderly with mental 
or acute physical illness were excluded. According to the requirement for multivariate analysis, the sample size was 5-10 times that of the number of study variables. In this study, 26 factors were investigated, and the minimum sample size was 130. Eventually, we investigated a total of 331 older people, which met the requirements of an adequate sample size. This study was approved by the medical ethics committee of Beijing PLA General Hospital (No.: S2018-048-01).

\section{Data collection and variables}

Two trained researchers engaged in geriatrics or geriatric nursing collected data by face-to-face interviews using a structured fall risk checklist. The interviewees were the elderly, their principal caregivers and family doctors (nurses). Written informed consent was obtained from the respondents before the investigation.

The survey items included gender, age, history of falls, diseases and symptoms, medications, difficulties with physical activity, psychological status, cognitive status, and abnormal behaviors of the elderly. Among them, diseases, symptoms, and medications were primarily obtained from medical and nursing records.

History of falls: The subjects were asked whether they had fallen within the past year. When the answer was "yes", they were further queried on whether they had been injured and if they had fallen $\geq 2$ times. We defined a 'severe fall' by the occurence of fall-related injuries or when the number of falls $\geq 2$ times.

Diseases and symptoms: The subjects were asked whether they had ischemic heart disease, hypertension, stroke, diabetes, Parkinson's disease, urinary incontinence/frequent urination, orthostatic hypotension, dizziness while standing, and sensory disturbances. Sensory disturbances primarily included vision/hearing loss and numbness/pain in legs and feet.

Medications: The subjects were asked about their fall-risk related medications, including sedative hypnotics (ATC N05C), antipsychotics (ATC N05A), diuretics (ATC C03), and antihistamines (ATC R06). In addition, the elderly subjects were queried on whether they had a history of multiple-drug use involving more than four types of drugs.

Difficulties with physical activity: The subjects were asked whether they felt unstable while walking; whether hand support was necessary when getting up from a chair; whether crutches, walking aids, and other auxiliary equipment were needed for conducting daily activities.

Psychological status: The subjects were asked whether they suffered from insomnia/early awakening, depression, and the fear of falling.

Cognitive status: The subjects were asked whether they were able to communicate normally, and comprehend and follow the instructions of doctors and nurses. Based on the responses of "always", "sometimes", and "cannot", the cognitive status of the subjects was divided into "normal", "mild disorder", and "moderate/severe disorder". 
Abnormal behaviors: The subjects were asked whether or not they followed necessary safety measures and whether they had been loitering.

\section{Statistical analysis}

SPSS24.0 statistical software was used for data analysis. The general information and main variables of the study were described by mean value, standard deviation, frequency, and percentage. A quantilequantile plot (Q-Q plot) was performed to analyze the normality of variables. The chi-square test was used for univariate analysis. Following univariate analysis, a forward binary logistic regression analysis was performed to identify the independent risk factors of falls, recurrent falls, or fall-related injuries of the elderly. The Hosmer-Lemeshow statistics were used to test the goodness-of-fit of the model. Eventually, the ability of the model to identify fall risk in the elderly was quantified by the area under the receiver operating characteristic curve (AUC). $p<0.05$ was considered statistically significant.

\section{Results}

\section{General information and falls of the elderly}

The age range of the 331 subjects was 65-104 years with an average age of $83.83 \pm 6.37$ years old. Among them, $60.4 \%$ were female, and $39.6 \%$ were male. In the past year, 142 subjects (42.9\%) had experienced falls, and 102 subjects $(30.8 \%)$ had serious falls.

\section{Analysis of the factors causing falls/severe falls in the elderly living in senior apartments}

The results of the univariate analysis for falls and severe falls are shown in Tables 1 and 2 . The variables of statistical significance were included in a logistic regression model for multivariate analysis. The results showed that female gender $(\mathrm{OR}=2.307)$, older age $(\mathrm{OR}=4.724,4.435$, and 10.080 corresponded to $75-84,85-94$, and $\geq 95$ years of age respectively), urinary incontinence/frequency $(O R=2.254)$, and unsteady gait $(\mathrm{OR}=4.400)$ were independently associated with falls among the elderly $($ Table 3$)$. In addition, female gender $(O R=2.289)$, urinary incontinence/frequency $(O R=2.004)$, and unsteady gait (OR = 3.612) were also closely related to severe falls in the elderly, including recurrent falls and fall-related injuries (Table 4). 
Table 1

Univariate analysis of falls in the elderly $(\mathrm{n}=331)$

\begin{tabular}{|c|c|c|c|c|c|}
\hline Risk factors & Overall n(\%) & Falls n(\%) & No falls n(\%) & $x^{2}$ & $p$ \\
\hline \multicolumn{6}{|l|}{ Demographic data } \\
\hline \multicolumn{6}{|l|}{ Gender } \\
\hline Male & 131(39.6) & $47(14.2)$ & $84(25.4)$ & 4.365 & $0.037^{\star}$ \\
\hline Female & $200(60.4)$ & 95(28.7) & 105(31.7) & & \\
\hline \multicolumn{6}{|l|}{ Age } \\
\hline $65-74$ & $27(8.2)$ & $4(1.2)$ & $23(6.9)$ & 15.800 & $0.001 * *$ \\
\hline $75-84$ & $136(41.1)$ & $56(16.9)$ & $80(24.2)$ & & \\
\hline $85-94$ & $155(46.8)$ & $72(21.7)$ & $83(25.1)$ & & \\
\hline$\geq 95$ & $13(3.9)$ & $10(3.0)$ & $3(0.9)$ & & \\
\hline \multicolumn{6}{|l|}{ Diseases and symptoms } \\
\hline Ischemic heart disease & $228(68.9)$ & $100(30.2)$ & $128(38.7)$ & 0.275 & 0.600 \\
\hline Hypertension & $172(52.0)$ & $72(21.8)$ & $100(30.2)$ & 0.158 & 0.691 \\
\hline Diabetes & $59(17.8)$ & $28(8.4)$ & $31(9.4)$ & 0.609 & 0.435 \\
\hline Stroke & $111(33.5)$ & $53(16.0)$ & $58(17.5)$ & 1.602 & 0.206 \\
\hline Parkinson's disease & $15(4.5)$ & $9(2.7)$ & $6(1.8)$ & 1.875 & 0.171 \\
\hline Urinary incontinence / frequency & $171(51.7)$ & $91(27.5)$ & $80(24.2)$ & 15.369 & $<0.001^{\star *}$ \\
\hline Orthostatic hypotension & $17(5.1)$ & $9(2.7)$ & $8(2.4)$ & 0.738 & 0.390 \\
\hline Dizziness while standing & $101(30.5)$ & $48(14.5)$ & $53(16.0)$ & 1.269 & 0.260 \\
\hline Vision/hearing loss & $208(62.8)$ & $94(28.4)$ & $114(34.4)$ & 1.200 & 0.273 \\
\hline Numbness/pain in legs and feet & $91(27.5)$ & $43(13.0)$ & $48(14.5)$ & 0.971 & 0.325 \\
\hline \multicolumn{6}{|l|}{ Drugs } \\
\hline Sedative hypnotics & $82(24.8)$ & $38(11.5)$ & $44(13.3)$ & 0.527 & 0.468 \\
\hline Antipsychotics & $92(27.8)$ & $48(14.5)$ & $44(13.3)$ & 4.473 & $0.034^{*}$ \\
\hline Diuretics & $24(7.3)$ & $8(2.4)$ & $16(4.8)$ & 0.967 & 0.325 \\
\hline
\end{tabular}

*Significant to the 0.05 level **Significant to the 0.01 level 


\begin{tabular}{|c|c|c|c|c|c|}
\hline Risk factors & Overall n(\%) & Falls n(\%) & No falls $n(\%)$ & $x^{2}$ & $p$ \\
\hline Antihistamines & $38(11.5)$ & $21(6.3)$ & $17(5.1)$ & 2.678 & 0.102 \\
\hline Multiple-drug & $201(60.7)$ & $95(28.7)$ & $106(32.0)$ & 3.978 & $0.046^{\star}$ \\
\hline \multicolumn{6}{|l|}{ Difficulties with physical activity } \\
\hline Conscious unstable walking & 209(63.1) & 118(35.6) & $91(27.5)$ & 42.558 & $<0.001^{* *}$ \\
\hline Dysstasia & 242(73.1) & $121(36.6)$ & $121(36.6)$ & 18.520 & $<0.001^{\star *}$ \\
\hline Walking aids & 176(53.2) & $100(30.2)$ & $76(23.0)$ & 29.721 & $<0.001^{\star *}$ \\
\hline \multicolumn{6}{|l|}{ Psychological status } \\
\hline Insomnia/early awakening & $145(43.8)$ & $66(19.9)$ & $79(23.9)$ & 0.721 & 0.396 \\
\hline Depression & $124(37.5)$ & $59(17.8)$ & $65(19.6)$ & 1.773 & 0.183 \\
\hline Fear of falling & $229(69.2)$ & 107(32.3) & $122(36.8)$ & 4.438 & $0.035^{\star}$ \\
\hline \multicolumn{6}{|l|}{ Cognitive status } \\
\hline Normal & 156(47.1) & $54(16.3)$ & 102(30.8) & 8.423 & $0.015^{\star}$ \\
\hline Mild & $98(29.6)$ & $48(14.5)$ & $50(15.1)$ & & \\
\hline Moderate/severe & $77(23.3)$ & $40(12.1)$ & $37(11.2)$ & & \\
\hline \multicolumn{6}{|l|}{ Abnormal behaviors } \\
\hline $\begin{array}{l}\text { Lack of compliance with safety } \\
\text { measures }\end{array}$ & $128(38.7)$ & $69(20.8)$ & $59(17.8)$ & 10.321 & $0.001^{\star \star}$ \\
\hline Loitering behaviors & $73(22.1)$ & $38(11.5)$ & $35(10.6)$ & 3.204 & 0.073 \\
\hline \multicolumn{6}{|l|}{ *Significant to the 0.05 level } \\
\hline$\star \star$ Significant to the 0.01 level & & & & & \\
\hline
\end{tabular}


Table 2

Univariate analysis of severe falls in the elderly $(n=331)$

\begin{tabular}{|c|c|c|c|c|}
\hline Risk factors & $\begin{array}{l}\text { Fall-related injuries or } \\
\text { falls } \geq 2 \text { times } n(\%)\end{array}$ & $\begin{array}{l}\text { Falls } \leq 1 \text { time and } \\
\text { without injuries } n(\%)\end{array}$ & $x^{2}$ & $p$ \\
\hline \multicolumn{5}{|l|}{ Demographic data } \\
\hline \multicolumn{5}{|l|}{ Gender } \\
\hline Male & $30(9.1)$ & $101(30.5)$ & 6.371 & $0.012^{\star}$ \\
\hline Female & $72(21.8)$ & $128(38.7)$ & & \\
\hline \multicolumn{5}{|l|}{ Age } \\
\hline $65-74$ & $4(1.2)$ & $23(6.9)$ & 9.559 & $0.023^{*}$ \\
\hline $75-84$ & $45(13.6)$ & $91(27.5)$ & & \\
\hline $85-94$ & $45(13.6)$ & 110(33.2) & & \\
\hline$\geq 95$ & $8(2.4)$ & $5(1.5)$ & & \\
\hline \multicolumn{5}{|l|}{$\begin{array}{l}\text { Diseases and } \\
\text { symptoms }\end{array}$} \\
\hline $\begin{array}{l}\text { Ischemic heart } \\
\text { disease }\end{array}$ & $73(22.0)$ & $155(46.8)$ & 0.496 & 0.481 \\
\hline Hypertension & $51(15.4)$ & $121(36.6)$ & 0.228 & 0.633 \\
\hline Diabetes & $24(7.2)$ & $35(10.6)$ & 3.276 & 0.070 \\
\hline Stroke & $43(13.0)$ & $68(20.5)$ & 4.917 & $0.027^{\star}$ \\
\hline Parkinson's disease & $7(2.1)$ & $8(2.4)$ & 1.852 & 0.174 \\
\hline $\begin{array}{l}\text { Urinary incontinence } \\
\text { / frequency }\end{array}$ & $66(20.0)$ & 105(31.7) & 10.045 & $0.002^{\star \star *}$ \\
\hline $\begin{array}{l}\text { Orthostatic } \\
\text { hypotension }\end{array}$ & $8(2.4)$ & $9(2.7)$ & 2.218 & 0.136 \\
\hline $\begin{array}{l}\text { Dizziness while } \\
\text { standing }\end{array}$ & $34(10.3)$ & $67(20.2)$ & 0.553 & 0.457 \\
\hline Vision/hearing loss & $70(21.1)$ & $138(41.7)$ & 2.115 & 0.146 \\
\hline $\begin{array}{l}\text { Numbness/pain in } \\
\text { legs and feet }\end{array}$ & $27(8.2)$ & 64(19.3) & 0.077 & 0.781 \\
\hline
\end{tabular}

*Significant to the 0.05 level

**Significant to the 0.01 level 


\begin{tabular}{|c|c|c|c|c|}
\hline Risk factors & $\begin{array}{l}\text { Fall-related injuries or } \\
\text { falls } \geq 2 \text { times } n(\%)\end{array}$ & $\begin{array}{l}\text { Falls } \leq 1 \text { time and } \\
\text { without injuries } n(\%)\end{array}$ & $x^{2}$ & $p$ \\
\hline Sedative hypnotics & $29(8.8)$ & $53(16.0)$ & 1.059 & 0.304 \\
\hline Antipsychotics & $37(11.2)$ & $55(16.6)$ & 5.283 & $0.022^{\star}$ \\
\hline Diuretics & $8(2.4)$ & $16(4.8)$ & 0.077 & 0.782 \\
\hline Antihistamines & 19(5.7) & 19(5.7) & 7.411 & $0.006^{\star *}$ \\
\hline Multiple-drug & $68(20.5)$ & 133(40.2) & 2.182 & 0.140 \\
\hline \multicolumn{5}{|l|}{$\begin{array}{l}\text { Difficulties with } \\
\text { physical activity }\end{array}$} \\
\hline $\begin{array}{l}\text { Conscious unstable } \\
\text { walking }\end{array}$ & $84(25.4)$ & $125(37.8)$ & 23.380 & $<.001^{\star *}$ \\
\hline Dysstasia & $90(27.2)$ & 152(45.9) & 17.153 & $\begin{array}{l}<.001^{* *} \\
\end{array}$ \\
\hline Walking aids & $71(21.4)$ & 105(31.7) & 15.995 & $<.001^{\star *}$ \\
\hline \multicolumn{5}{|l|}{ Psychological status } \\
\hline $\begin{array}{l}\text { Insomnia/early } \\
\text { awakening }\end{array}$ & $46(13.9)$ & 99(29.9) & 0.100 & 0.752 \\
\hline Depression & $47(14.2)$ & $77(23.3)$ & 4.672 & $0.031^{\star}$ \\
\hline Fear of falling & $78(25.6)$ & $151(45.6)$ & 3.671 & 0.055 \\
\hline \multicolumn{5}{|l|}{ Cognitive status } \\
\hline Normal & $36(10.9)$ & $120(36.2)$ & 8.706 & $0.013^{\star}$ \\
\hline Mild & $35(10.6)$ & $63(19.0)$ & & \\
\hline Moderate/severe & $31(9.4)$ & 46(13.9) & & \\
\hline \multicolumn{5}{|l|}{ Abnormal behaviors } \\
\hline $\begin{array}{l}\text { Lack of compliance } \\
\text { with safety } \\
\text { measures }\end{array}$ & $52(15.7)$ & $76(23.0)$ & 9.420 & $0.002^{\star *}$ \\
\hline Loitering behaviors & $27(8.2)$ & $46(13.9)$ & 1.673 & 0.196 \\
\hline \multicolumn{5}{|c|}{ *Significant to the 0.05 level } \\
\hline$\star \star$ Significant to the 0 & level & & & \\
\hline
\end{tabular}


Table 3

Binary Logistic regression analysis of fall risks among the elderly

\begin{tabular}{|llll|}
\hline Risk factors & OR & $p$ & $95 \%$ Cl for OR \\
\hline Gender (Female) & 2.307 & 0.001 & $1.378-3.864$ \\
\hline Age & & & \\
\hline $75-84$ & 4.724 & 0.012 & $1.403-15.903$ \\
\hline $85-94$ & 4.435 & 0.015 & $1.330-14.787$ \\
\hline$\geq 95$ & 10.080 & 0.010 & $1.742-58.322$ \\
\hline Urinary incontinence / frequency & 2.254 & 0.002 & $1.359-3.740$ \\
\hline Unstable walking & 4.400 & $<0.001$ & $2.523-7.673$ \\
\hline Hosmer and Lemeshow Test, $p=0.993$ & & \\
\hline
\end{tabular}

OR odds ratio, $\mathrm{Cl}$ confidence interval

Table 4

Binary Logistic regression analysis of severe falls among the elderly

\begin{tabular}{|llll|}
\hline Risk factors & OR & $\boldsymbol{p}$ & $95 \%$ Cl for OR \\
\hline Gender (Female) & 2.289 & 0.002 & $1.344-3.896$ \\
\hline Urinary incontinence / frequency & 2.004 & 0.008 & $1.196-3.358$ \\
\hline Unstable walking & 3.612 & $<0.01$ & $2.005-6.507$ \\
\hline Hosmer and Lemeshow Test, $p=0.954$ & & \\
\hline
\end{tabular}

OR odds ratio, $\mathrm{Cl}$ confidence interval

\section{Predictive ability of the model on fall risks in the elderly}

Four independent risk factors for falls were identified based on logistic regression analysis. The proportion of falls corresponding to different independent predictors among 331 older people are shown in Fig. 1. The incidence of falls increased from $0 \%$ for zero risk factors to $71.0 \%$ for four risk factors.

The ROC curve (Fig. 2) was obtained based on the fall risk prediction model, with an AUC of 0.749 (95\% Cl: $0.697-0.801, p<0.001)$ and a cut-off value of 0.355 . The corresponding sensitivity and specificity were $82.4 \%$ and $57.1 \%$, respectively.

\section{Discussion}

Our study found that the incidence of falls in senior apartments in the past year was $42.9 \%$. Moreover, $30.8 \%$ of the elderly had suffered recurrent falls or fall-related injuries. The incidence of falls was slightly 
higher than that reported by the World Health Organization (28\%-35\%) [18]. The average age of the elderly in senior apartments is high, and their physical health condition is relatively poor in the present study. Therefore, they are more prone to falls than the elderly elsewhere. Research has shown that about $40 \%$ of the elderly who live in pension-based institutions do so in part due to falls[19]. It also reminds us that falls among the elderly living in senior apartments are worthy of attention and it is necessary to analyze the causes of falls and formulate targeted intervention strategies.

To classify different fall outcomes, we compared and analyzed the results of fall events in senior apartments using two separate criteria (falls vs. no falls; number of falls $\leq 1$ time and without injury vs. fall-related injuries or number of falls $\geq 2$ ), which is consistent with the literature [20]. It was found that gender, urinary incontinence/frequency, and unsteady gait were the primary factors predicting falls, recurrent falls, or fall-related injuries among the elderly in senior apartments. Furthermore, age was a critical predictor of falls in the elderly. Compared with the elderly in the age range of 65 to 74 years, the fall risk of the elderly over 75 years of age was 3 times higher, and that of the elderly over 95 years of age was 9 times higher, supporting the conjecture of the elderly in senior apartments having an increased incidence of falls due to their older age.

Marta et al. [21] performed a prospective cohort study on falls among the elderly in 37 pension-based institutions in Spain (average age $=82$ years). Their results also confirmed that old age was a risk factor for falls, and those who fell were two years older than those who did not. However, we did not find an independent effect of age on recurrent falls or fall-related injuries in the elderly. This could be ascribed to the fact that the characteristics of people prone to recurrent falls and fall-related injuries were more stable and independent of age. Tinetti et al. [22] demonstrated that the risk factors were the same in the elderly with one fall and those with multiple falls, and the fall risk increased linearly with the number of risk factors, which is consistent with the conclusion of the current study.

The effect of gender on falls among the elderly in our study is consistent with other studies [23-25]. It was shown that older females were more likely to fall than older males and more than twice as likely to have recurrent falls and fall-related injuries $(\mathrm{OR}=2.289,95 \% \mathrm{Cl}: 1.344-3.896)$. This could be related to the decreased estrogen, osteoporosis, decreased muscle content, poor muscle strength, and a decline in lower limb strength in elderly females [26, 27]. Additionally, we found that the elderly with urinary incontinence or frequent urination were at high risk of falls, recurrent falls, and fall-related injuries. The risk was twice as high as the average elderly, consistent with a previous study [28]. The higher risk of falls in these cases was primarily due to the frequent use of toilets. Research has shown that the elderly are prone to falls when they rush to bathrooms which are the most common locations for falls $[29,30]$. Unstable walking is the most direct manifestation of decreased physical functioning, balance, and limb coordination in the elderly. Our study showed that the elderly with conscious unsteady gait had a higher risk of falls and fallrelated injuries. This result was indeed expected, given that the falls resulted from physical imbalance.

Fall risk has long been considered as being multifactorial. Our results showed that the incidence of falls increased significantly with increased risk factors and underscored the need for senior apartments to 
develop targeted fall prevention intervention measures for the elderly. The formulation of measures should be conducted based on risk screening. Additionally, our study performed structured interviews to determine fall risk factors. The information was easy to obtain, and the sensitivity of the fall risk prediction model used was more than $80 \%$, providing a reference for rapid and simple screening of the elderly with high fall risks in senior apartments. However, this study is a retrospective study. There may be recall bias in some of the information obtained, and most of the data are subjective indicators. Our study lacks quantitative tests of muscle strength, gait speed, and balance, with some exceptions. A prospective cohort study will be conducted in the future to demonstrate the predictive accuracy of the model.

\section{Conclusions}

Our study showed that the elderly who are female, have urinary incontinence/frequency, and have a conscious unsteady gait are more likely to have falls, recurrent falls, and fall-related injuries. Moreover, the overall risk of falls significantly increases with age and the number of risk factors. Hence, the risk factors mentioned above should be considered when formulating relevant fall prevention measures for the elderly. This study also provides a reliable method for rapid and simple screening of older people at a high risk of falls. However, this study is a retrospective study, and further research is necessary to verify the predictive accuracy of the model on falls in the elderly.

\section{Declarations}

\section{Competing interest}

The authors declare that they have no competing interest.

\section{Author's contribution}

SQQ, SM, and PHY conceived the study, contributed to study design, obtained the funding for the study, and were responsible to the conduct of the study. SQQ, ZJ, MYZ, and SJ contributed to data analysis. All authors contributed toward the writing of the manuscript and approved the final submitted version.

\section{Funding}

This work was supported by the National Key Research and Development Program of China(2018YFC2001400). There were no significant interactions between the researchers and the funding body regarding the study design; data collection, analysis, and manuscript writing.

\section{Availability of data and materials}

The data that support the findings of this study are available from the corresponding author upon request.

\section{Ethics approval and consent to participate}


The studies involving human participants were reviewed and approved by Chinese PLA General Hospital Medical Ethics Committee (No.: S2018-048-01). All procedures involving human participants were performed in accordance with the ethical standards of the Ethics Committee for Clinical Research of Chinese PLA General Hospital and with the Declaration of Helsinki and its later amendments. The participants provided their written informed consent to participate in this study.

\section{Consent for publication}

Not applicable.

\section{References}

1. Ahn S, Oh J. Effects of a health-belief-model-based osteoporosis- and fall-prevention program on women at early old age. Appl Nurs Res. 2021;59:151430.

2. Sterling DA, O’Connor JA, Bonadies J. Geriatric falls: injury severity is high and disproportionate to mechanism. J Trauma. 2021;50:116-119.

3. Centers for Disease Control and Prevention, National Center for Injury Prevention and Control. Webbased Injury Statistics Query and Reporting System (WISQARS).

https://webappa.cdc.gov/sasweb/ncipc/mortrate.html. Accessed 30 November 2010

4. World Health Organization (WHO). Falls fact sheet. https://www.who.int/en/news-room/factsheets/detail/falls. Accessed 16 January 2018.

5. Lu ZM, Wang Y, Ye PP, Er YL, Duan LL. Analysis on epidemiologic characteristics of fall in old people: results from Chinese National Injury Surveillance System, 2015-2018.Chin J Epidemiol. 2021;42:137-141.

6. Khurrum M, Chehab M, Ditillo M, Richards J, Douglas M, Bible L, Spece L, Joseph B. Trends in Geriatric Ground-Level Falls: Report from the National Trauma Data Bank. J Surg Res. 2021;266:261-268.

7. Peeters GMEE, Pluijm SMF, Schoor NM, Elder PJM, Bouter LM, Lips P. Validation of the LASA fall risk profile for recurrent falling in older recent fallers. J Clin Epidemiol. 2010;63:1242-1248.

8. Hausdorff JM, Rios DA, Edelber HK. Gait variability and fall risk in community-living older adults: a 1year prospective study. Arch Phys Med Rehabil. 2001;82:1050-1056.

9. Yao Q, Jin W, Li Y. Associations between fear of falling and activity restriction and late life depression in the elderly population: Findings from the Irish longitudinal study on ageing (TILDA). J Psychosom Res. 2021;146:110506.

10. Cumming R, Salkeld G, Thomas M, Szonyi G. Prospective study of the impact of fear of falling on activities of daily living, SF-36 Scores, and nursing home admission. J Gerontol A Biol Sci Med Sci. 2000;55:M299-M305.

11. Cameron ID, Dyer SM, Panagoda CE, Murray GR, Hill KD, Cumming R G, Kerse N. Interventions for preventing falls in older people in care facilities and hospitals. Cochrane Database Syst Rev. 2018; 
http://doi.org/ 10.1002/14651858.CD005465.pub4

12. Yuan JL, Zhao RX, Ma YJ, Li XD, Zhou XM, Wang XF, Jiang XY, Li SJ. Prevalence/potential risk factors for motoric cognitive risk and its relationship to falls in elderly Chinese people: a crosssectional study. Eur J Neurol. 2021;28:2680-2687.

13. Teng Z, Zhu Y, Teng Y, Long Q, Hao Q, Yu X, Yang L, Lv Y, Liu J, Zeng Y, Lu S. The analysis of osteosarcopenia as a risk factor for fractures, mortality, and falls. Osteoporos Int. 2021; http://doi.org/10.1007/s00198-021-05963-x

14. Feng F, Shi G, Chen H, Jia P, Bao L, Xu F, Sun QC, Tang H. Comprehensive Interventions Including Vitamin D Effectively Reduce the Risk of Falls in Elderly Osteoporotic Patients. Orthop Surg. 2021;13:1262-1268.

15. Meng ZM, Li Z. Study on Classification Standards and Classification Management of Aged Care Institutions. Journal of Jiangsu University(Social Science Edition). 2018;20:71-78.

16. Delbaere K, Close JC, Menz HB, Cumming RG, Cameron ID, Sambrook PN, March LM, Lord SR. Development and validation of fall risk screening tools for use in residential aged care facilities. Med J Aust. 2008;189:193-196.

17. Nevitt MC, Cummings SR, Kidd S, Black D. Risk factors for recurrent nonsyncopal falls: a prospective study. JAMA-J Am Med Assoc. 1989;261:2663-2668.

18. World Health Organization. World report on aging and Health. Geneva, WHO 2015 2:5-42.

19. Tinetti ME, Speechley M, Ginter SF. Risk factors for falls among elderly persons living in the community. N Engl J Med. 1988;319:1701-1707.

20. Fletcher, Paula C. Risk Factors for Falling Among Community-Based Seniors Using Home Care Services. J Gerontol. 2002;57A:M504-M510.

21. Aranda-Gallardo M, Morales-Asencio JM, Margarita LR, Vazquez-Blanco MJ, Morilla-Herrera JC, Rivas-Ruiz F, Toribio-Montero JC, Canca-Sanchez JC. Characteristics, consequences and prevention of falls in institutionalised older adults in the province of Malaga (Spain): a prospective, cohort, multicentre study. BMJ Open. 2018;8:e020039.

22. Nicken H. Intrinsic factors in falling among the elderly. Arch Intern Med. 1985;145:1089-1093.

23. Cao WZ, Hang YY, Xi SX. Meta-analysis of risk factors for fall in Chinese elderly. Chinese Nursing Research. 2018;32:3222-3228.

24. Çeçen D, Özbayır T. Evaluation of practice's related to falling prevention and determination of falling risk of elderly patients who are treated in surgical clinics. Ege Üniversitesi Hemşirelik Yüksek Okulu Dergisi. 2011;27:11-23.

25. Cevizci S, Uluocak S, Aslan C, Gökulu G, Bakar C. Prevalence of falls and associated risk factors among aged population: community based cross-sectional study from Turkey. Cent Eur J Public Health. 2015;23:233-239.

26. Michel HB, Joseph PD, Marike RH, Jolanda CVH, Harry FC, Jacques TVE. Relationship between location and activity in injurious falls: an exploratory study. BMC Geriatrics. 2010;10:40-48. 
27. Ahn S, Oh J. Effects of a health-belief-model-based osteoporosis- and fall-prevention program on women at early old age. Appl Nurs Res. 2021;59:151430.

28. Damián J, Pastor-Barriuso R, Valderrama-Gama E, Pedro-Cuesta JD. Factors associated with falls among older adults living in institutions. BMC Geriatrics. 2013;13:6.

29. Son B, Akishita M, Uchiyama E, Imaeda S, Taniguchi S, Sumikawa Y, Unyaporn S, Matsubara T, Tanaka S, Tanaka T, Otsuki T, Okata J, lijima K. Multiple turns: Potential risk factor for falls on the way to the toilet. Geriatr Gerontol Int. 2019;19:1293-1295.

30. Jiang Y, Xia Q, Zhou P, Jiang S, Xu B. Environmental hazards increase the fall risk among residents of long-term care facilities: a prospective study in Shanghai, China. Age and Ageing. 2020; 50:875-881.

Figures

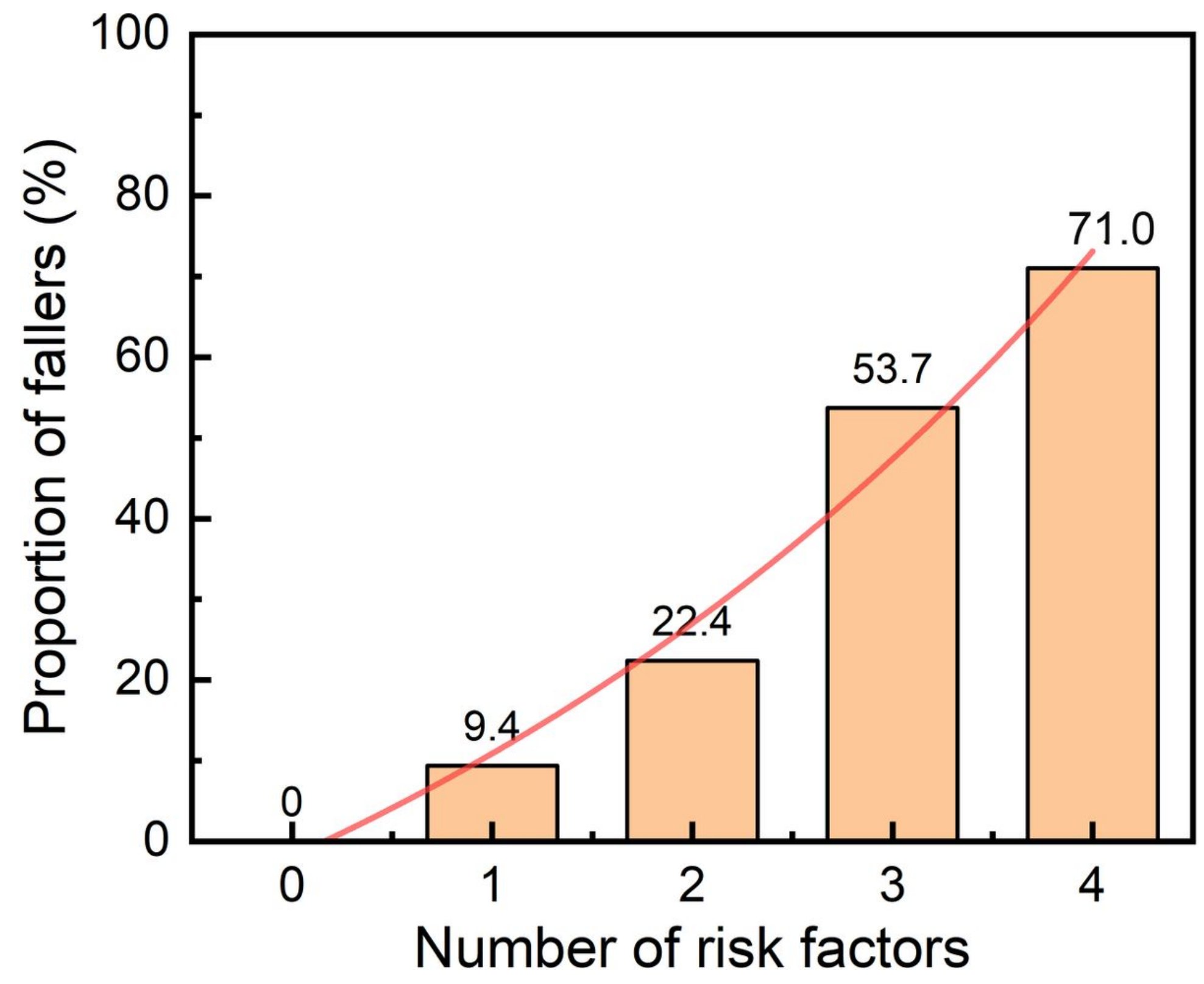

Figure 1 
The proportion of falls corresponding to different independent predictors. Four independent risk factors for falls were identified by logistic regression analysis: female, older age, urinary incontinence/frequency, and unsteady gait

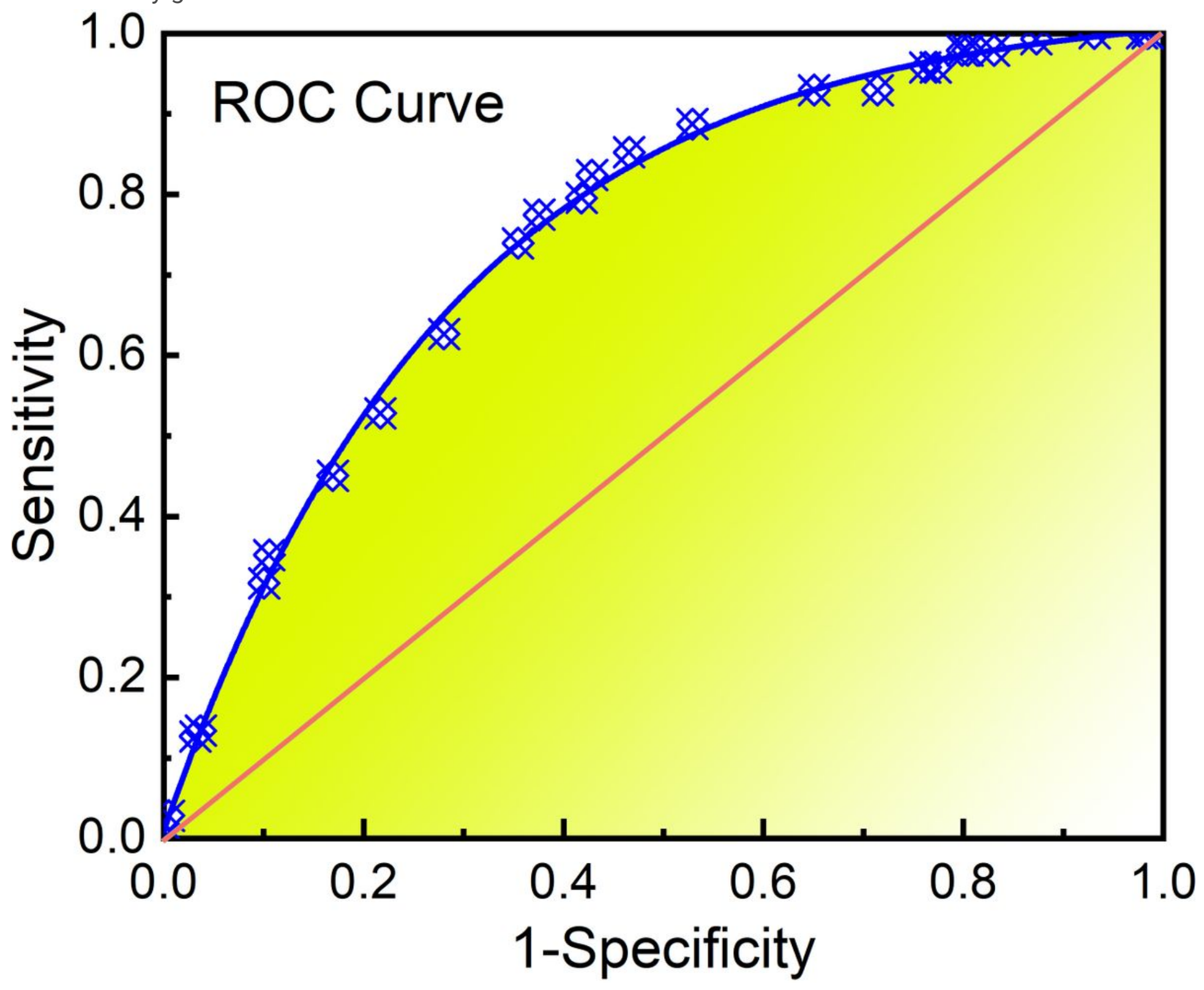

Figure 2

ROC curve for the fall risk prediction model of the elderly 